\title{
Comparison of invasive and noninvasive saturation monitoring in prescribing oxygen during exercise in COPD patients
}

\author{
M. Carone, A. Patessio, L. Appendini, A. Purro, E. Czernicka, \\ S. Zanaboni, C.F. Donner
}

Comparison of invasive and noninvasive saturation monitoring in prescribing oxygen during exercise in COPD patients. M. Carone, A. Patessio, L. Appendini, A. Purro, E. Czernicka, S. Zanaboni, C.F. Donner. (CERS Journals Ltd 1997.

ABSTRACT: The aim of this study was to determine whether it is possible using ear-oximetry to prescribe the correct oxygen flow rates during exercise in chronic obstructive pulmonary disease (COPD) patients on long-term oxygen therapy (LTOT).

Twenty COPD patients on LTOT, with exercise desaturation breathing oxygen at resting flow rates, performed a series of 6-min treadmill walking tests, with a progressive increase in oxygen flows until oxygen saturation measured by ear- or pulse-oximetry $\left(S_{\mathrm{p}, \mathrm{O}_{2}}\right)$ was above $90 \%$. The exercise studies were repeated the next day, saturation being measured both noninvasively by ear-oximetry $\left(S \mathrm{p}, \mathrm{O}_{2}\right)$ and invasively by $\mathrm{CO}$-oximeter $\left(\mathrm{Sa}_{\mathrm{a}} \mathrm{O}_{2}\right)$. The exercise studies continued until both $\mathrm{Sa}_{\mathrm{a}}, \mathrm{O}_{2}$ and $S \mathrm{p}, \mathrm{O}_{2}$ were above $90 \%$. Reproducibility and agreement of the results were analysed according to Bland and Altman.

$\mathrm{Sp}_{\mathrm{O}, \mathrm{O}_{2}}$ was significantly lower than $\mathrm{Sa}_{\mathrm{a}} \mathrm{O}_{2}$ by, on average, $0.7 \%(\mathrm{p}<0.004) . \mathrm{Sp}_{2} \mathrm{O}_{2}$ reproducibility between the two days was good. The invasive and noninvasive oxygen flow prescriptions agreed in only 10 subjects; in six subjects ear-oximetry overestimated the oxygen supply $(\mathrm{p}<\mathbf{0 . 0 0 0 5})$, whilst in four subjects it underestimated $(\mathrm{p}<0.01)$.

Contingency table analysis with coded raw data for the values of the sixth minute (that of the deepest desaturation) showed poor agreement between $\mathrm{CO}$ - and pulse-

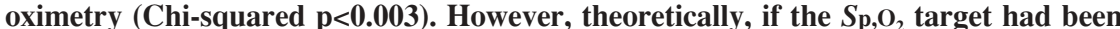
raised to $93 \%$, there would have been hardly any underestimations of $\mathrm{Sa}_{\mathrm{a}} \mathrm{O}_{2} \mathrm{p}=\mathrm{NS}$ ).

We concluded that noninvasive measurement of oxygen saturation is not adequate for estimating arterial saturation in chronic obstructive pulmonary disease. We suggest, as a working solution, that a new cut-off limit of $93 \%$ oxygen saturation measured by pulse oximetry should be used as the value below which exercise-induced desaturation should be corrected in order to allow oxygen to be properly prescribed during activities of daily life.

Eur Respir J 1997; 10: 446-451.
Salvatore Maugeri Foundation, IRCCS, Rehabilitation Institute, Division of Pulmonary Disease, Veruno (NO), Italy.

Correspondence: M. Carone

Fondazione Salvatore Maugeri

IRCCS

Istituto di Riabilitazione

Divisione di Pneumologia

Via Revislate 13

28010 Veruno $(\mathrm{NO})$

Italy

Keywords: Exercise

lung disease (obstructive)

oximetry

oxygen inhalation therapy

Received: December 121995

Accepted after revision October 261996
It is a well-known finding that long-term oxygen therapy (LTOT) improves the survival $[1,2]$ and haemodynamics [3, 4] of hypoxaemic patients with chronic obstructive pulmonary disease (COPD). These benefits are greater if arterial oxygen saturation $\left(\mathrm{Sa}_{\mathrm{a}} \mathrm{O}_{2}\right)$ is restored to above $90 \%$ for at least $18 \mathrm{~h} \cdot$ day $^{-1}[5,6]$. In addition, supplemental oxygen has been found to increase exercise tolerance and reduce dyspnoea [7-9] in COPD patients who show exercise-induced desaturation. Therefore, it would seem desirable to be as precise as possible in correcting exercise desaturation in patients already on LTOT, even though it is not known whether supplemental oxygen during exercise further improves survival [9-11].

Both the evaluation of exercise desaturation and the prescription of oxygen flow rates can be made either invasively (by sampling arterial blood and directly reading its saturation on a CO-oximeter $\left.\left(\mathrm{Sa}_{\mathrm{a}} \mathrm{O}_{2}\right)\right)$, or noninvasively by ear- or pulse-oximetry $\left(\mathrm{S}, \mathrm{O}_{2}\right)$. In everyday clinical practice, the noninvasive method is used during submaximal exercise testing (e.g. 6-min walking test) [10-13].

The reliability of oximetry during exercise has been questioned $[14,15]$ when $\mathrm{Sp}, \mathrm{O}_{2}$ values below $90 \%$ are recorded $[15,16]$, and particularly when evidence of hypoxia exists in connection with exercise [17]. On the other hand, several studies have demonstrated that oximetry provides accurate measures of arterial oxygen saturation $\left(\mathrm{Sa}, \mathrm{O}_{2}\right)$ in subjects breathing hypoxic gas mixtures [18, 19], as well as in normal subjects [20], pulmonary patients [21], and trained athletes [22] during exercise. This would appear to be the case, in particular, if $\mathrm{Sp}, \mathrm{O}_{2}$ readings are interpreted against a baseline $\mathrm{Sa}_{\mathrm{a}} \mathrm{O}_{2}$ measured invasively at rest.

However, the impact of the potential inaccuracy of noninvasive methods on the prescription of supplemental oxygen, in terms of flow rates, remains to be studied. 
The aim of the present study was to determine the appropriateness of ear-oximetry in prescribing oxygen correctly (i.e. the precise oxygen flow needed to maintain $\mathrm{Sa}_{\mathrm{a}} \mathrm{O}_{2} \geq 90 \%$ throughout the exercise) during exercise in COPD patients on LTOT, who are likely to show more profound desaturations in response to exercise.

\section{Subjects}

Twenty patients (17 males and 3 females, aged $62 \pm 8$ yrs), with COPD according to the American Thoracic Society (ATS) criteria [9] were studied. All were on LTOT and experienced dyspnoea while performing activities of daily living or under moderate exertion. Before entering the study, all patients underwent a routine 6-min walking test (6-MWT), breathing oxygen at resting flow rates, during which they showed desaturation. All patients gave their informed consent.

Anthropometric parameters, arterial blood gases and pulmonary function test values are shown in table 1 .

\section{Methods}

\section{Determination of average speed}

All subjects performed three 6-min walking tests, according to the method first described in COPD patients by McGAvin et al. [23], and modified by ButLAND et al. [24]. The subjects were told that they could slow down or stop as necessary. The test was repeated three times in consideration of the learning effect [23, 25], and subjects were encouraged every $30 \mathrm{~s}$ [26]. A telemetric method was used to monitor electrocardiography (ECG) and heart rate (OTE Biomedica, Florence, Italy). The subjects performed the test breathing supplemental oxygen at the flow rate prescribed at rest (on average $\left.1.2 \pm 0.3( \pm \mathrm{SD}) \mathrm{L} \cdot \mathrm{min}^{-1}\right)$. The initial value of the oxygen saturation during that flow rate was on average $94 \pm 2 \%$. The oxygen was administered by means of a portable

Table 1. - Anthropometric parameters, arterial blood gas and pulmonary function test values

\begin{tabular}{lcc}
\hline Age & $\mathrm{yrs}$ & $62 \pm 8$ \\
$\mathrm{BMI}$ & $\mathrm{kg} \cdot \mathrm{m}^{-2}$ & $26.1 \pm 3.7$ \\
$\mathrm{pH}$ & $7.40 \pm 0.04$ \\
$\mathrm{~Pa}_{\mathrm{a}} \mathrm{O}_{2} \mathrm{kPa}$ & $7.5 \pm 0.7$ \\
$\mathrm{~Pa}_{\mathrm{C}} \mathrm{CO} \mathrm{K}_{2} \mathrm{kPa}$ & $6.4 \pm 1$ \\
$\mathrm{Sa}_{2} \%$ & $87 \pm 4$ \\
$\mathrm{FVC}$ & $\mathrm{L}$ & $1.7 \pm 0.45$ \\
& $\%$ pred & $47 \pm 9$ \\
$\mathrm{FEV} 1$ & $\mathrm{~L}$ & $0.86 \pm 0.23$ \\
& $\%$ pred & $31 \pm 8$ \\
$\mathrm{TLC}$ & $\mathrm{L}$ & $7.1 \pm 2.7$ \\
& $\%$ pred & $112 \pm 36$ \\
$\mathrm{RV}$ & $\mathrm{L}$ & $5.3 \pm 2.4$ \\
& $\%$ pred & $228 \pm 94$ \\
\hline
\end{tabular}

Data are presented as mean \pm SD. BMI: body mass index; $P_{\mathrm{a}, \mathrm{O}_{2}}$ : arterial oxygen tension; $\mathrm{Pa}_{\mathrm{a}} \mathrm{CO}_{2}$ : arterial carbon dioxide tension; $\mathrm{Sa}_{\mathrm{a}} \mathrm{O}_{2}$ : arterial oxygen saturation; FVC: forced vital capacity; FEV1: forced expiratory volume in one second; TLC: total lung capacity; RV: residual volume; \% pred: percentage of predicted value. source of liquid oxygen (Stroller; Vitalaire, Paris, France) through nasal prongs. The average speed was calculated by dividing the metres walked in the best test by 6 .

\section{Study protocol}

The study was carried out on two consecutive days. On the first day, spirometric function was recorded before the exercise tests. Forced expiratory volume in one second (FEV1) and forced vital capacity (FVC) were determined from the best of three FVC manoeuvres (PFT system; Mijnhardt, Bunnik, The Netherlands). Subjects then performed a 6-min treadmill (Woodway; Geres $\mathrm{GmbH}$, Loerrach, Germany) walking test while breathing oxygen at the resting flow rates. The treadmill speed was the average speed, as calculated in the preliminary test. The treadmill slope was $0 \%$.

Saturation was measured with a pulse oximeter by means of an ear probe (Biox 3760; Uhmeda, Louisville, USA), according to the manufacturer's instructions. The subject's ear lobe was massaged with isopropyl alcohol for $30 \mathrm{~s}$ to increase local perfusion. An ear probe stabilizer was placed over the ear and the transmission cable was routed under the chin to the opposite side of the patient's head, looped up and tucked inside an elastic headband. Finally, the ear probe was covered with a dark cloth to avoid light interference. Further 6-min treadmill tests were performed with a progressive increase (test after test) of oxygen flow rates, until the target saturation $\left(\mathrm{Sp}_{\mathrm{p}} \mathrm{O}_{2}\right)$ of above $90 \%$ was reached at times 2 , 4 and 6 min $\pm 4 \mathrm{~s}$. Oxygen flow rates were increased as follows: if the $\mathrm{Sp}, \mathrm{O}_{2}$ in the preceding 6-min treadmill test had been: 1) $86-90 \%$, in the successive test the increment was $1 \mathrm{~L} \cdot \mathrm{min}^{-1}$; 2) $81-85 \%$, the increment was $2 \mathrm{~L} \cdot \mathrm{min}^{-1}$; and 3) $<80 \%$, the increment was $3 \mathrm{~L} \cdot \mathrm{min}^{-1}$. Patients rested for $2 \mathrm{~h}$ between each exercise test.

On the second day, spirometry and exercise studies were repeated with the ear-oximeter and, in addition, a radial artery catheter. A blood sample was withdrawn at rest and every 2 min during the tests, and $\mathrm{Sa}_{\mathrm{a}} \mathrm{O}_{2}$ was measured using a CO-oximeter (IL 282; Instrumentation Laboratory, Lexington, USA). Calibration was performed before each test and confirmed daily with quality control ampoules. The exercise tests were continued, until both the invasively measured $\mathrm{Sa}_{2} \mathrm{O}_{2}$ and the ear-oximeter $\mathrm{Sp}, \mathrm{O}_{2}$ were above $90 \%$ at 2, 4 and $6 \mathrm{~min}$.

Thus, it was possible to compare the noninvasive versus invasive measurements, the repeatability of the earoximeter, and the noninvasive versus invasive oxygen flow rate prescriptions.

\section{Data analysis}

The agreement between ear-oximetry and CO-oximetry was assessed using the method described by BLAND and Altman [27]. Graphically, for each pair of measurements, the average value was plotted on the abscissa and the difference between the two values on the ordinate. The bias was estimated as the mean difference. The limits of agreement between the two methods were calculated as $\delta \pm 1.96 \mathrm{sD}$, where $\delta$ is the mean bias and SD the standard deviation of the individual differences. 
Whether the mean bias was significantly different from zero was determined by calculating the $95 \%$ confidence interval $(95 \% \mathrm{CI})$ of the bias. A p-value less than 0.05 was considered to be statistically significant. Dispersion around mean values was expressed as \pm 1 SD.

To verify the precision of the estimations, the $95 \%$ CI was calculated not only for the bias, but also for the upper and the lower limits. They were determined, respectively, as $\delta \pm(\mathrm{t} \times \mathrm{SE}$ of $\delta),(\delta+1.96 \mathrm{SD}) \pm(\mathrm{t} \times \mathrm{SE}$ of $\delta)$ and $(\delta-1.96 \mathrm{SD}) \pm(\mathrm{t} \times \mathrm{SE}$ of $\delta)$ where $\mathrm{t}$ is the value of the $t$ distribution with $n-1$ degrees of freedom in column

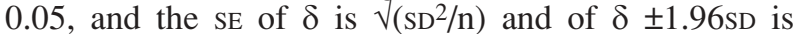
about $\sqrt{ }\left(3 \mathrm{SD}^{2} / \mathrm{n}\right)$.

Finally, the disagreement between $\mathrm{CO}$ - and ear-oximetry values was investigated with a contingency table $2 \times 2$ analysis by means of coded raw data. In this analysis, the sixth minute values of all the tests performed and successfully terminated (usually more than one per subject) were used, and not only that of the test in which the prescription was made. Obviously, the sixth minute was not always reached (i.e. because of severe desaturation or dyspnoea), so that it was only possible to compare 47 points registered during both invasive and noninvasive measurements. The sixth minute was chosen because it was usually the one with the deepest desaturations before the "correct" prescription of oxygen. The file, was recorded, transforming the numbers into "more" (more oxygen flow needed, i.e. increase oxygen flow rate) and "no more" (no more oxygen flow needed, i.e. flow is correct). In other words, when the cut-off value was a saturation of 90\%, "more" indicated a value below $90 \%$, and "no more" a value of $90 \%$ or above both for invasive and noninvasive readings.

\section{Results}

Resting lung function did not change over the 2 days of the study (table 2).

Firstly, the noninvasive versus invasive measurements of saturation were compared by plotting the difference between ear-oximeter and $\mathrm{CO}$-oximeter values against their mean values. Figure 1 shows all the values recorded at baseline and at the 2nd, 4th and 6th minute of each test. $\mathrm{Sp}, \mathrm{O}_{2}(90.1 \pm 5.0 \%)$ was significantly lower than $\mathrm{Sa}, \mathrm{O}_{2}(90.7 \pm 4.7 \%)$ (mean bias $-0.67 \pm 3.17 \%$; $\left.<<0.004\right)$.

Limits of agreement were +5.55 (upper limit) and -6.88 (lower limit). The $95 \%$ CI limits were -0.22 and -1.12 for the bias; 6.32 and 4.77 for the upper limit; -6.11 and -7.66 for the lower limit.

Table 2. - Difference in the pulmonary function tests between the two days of the study

\begin{tabular}{|c|c|c|}
\hline Parameter & Volume & p-value \\
\hline FVC 1st day & $1.72 \pm 0.51$ & \multirow{3}{*}{ NS } \\
\hline FVC 2nd day & $1.70 \pm 0.45$ & \\
\hline FEV1 1st day & $0.87 \pm 0.28$ & \\
\hline FEV1 2nd day & $0.86 \pm 0.23$ & NS \\
\hline
\end{tabular}

Data are presented as mean \pm SD. FVC: forced vital capacity; FEV1: forced expiratory volume in one second.

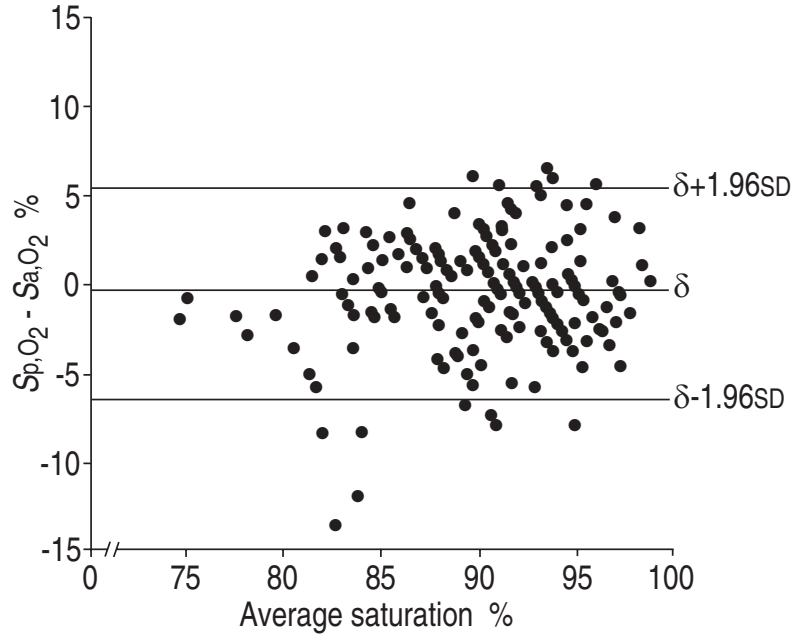

Fig. 1. - Plot of all the values recorded at baseline and at the 2nd, 4 th and 6th minute of each test. On the abscissa there is the average saturation value of each pair of measurements $\left(\left(\mathrm{Sp}, \mathrm{O}_{2}+\mathrm{Sa}, \mathrm{O}_{2}\right) / 2\right)$. On the ordinate there is the difference $(\delta)$ between the two values. Mean $\mathrm{Sp}, \mathrm{O}_{2}=90.1 \pm 5.0 \%$. Mean $\mathrm{Sa}, \mathrm{O}_{2} 90.7 \pm 4.7 \% . \delta=-0.67 \pm 3.17 \%(\mathrm{p}<0.004)$. $\mathrm{Sp}, \mathrm{O}_{2}$ : ear oximetry saturation; $\mathrm{Sa}, \mathrm{O}_{2}$ : arterial oxygen saturation; $\delta$ : mean bias; SD: standard deviation of the individual differences; $\delta+1.96 \mathrm{sD}$ : upper limit of agreement between the two methods; $\delta-1.96 \mathrm{sD}$ : lower limit of agreement between the two methods.

The same procedure was employed to assess the reproducibility of the ear-oximeter over the two days (fig. $2)$. There was no significant difference in ear-oximetry readings between the two days ( 1 st day mean $\pm \mathrm{SE} S \mathrm{p}, \mathrm{O}_{2} 89.5 \pm$ $5.1 \%$; 2 nd day $90.1 \pm 5.0 \%$ ) (mean bias $-0.23 \pm 3.61 \%$; $\mathrm{p}=$ NS).

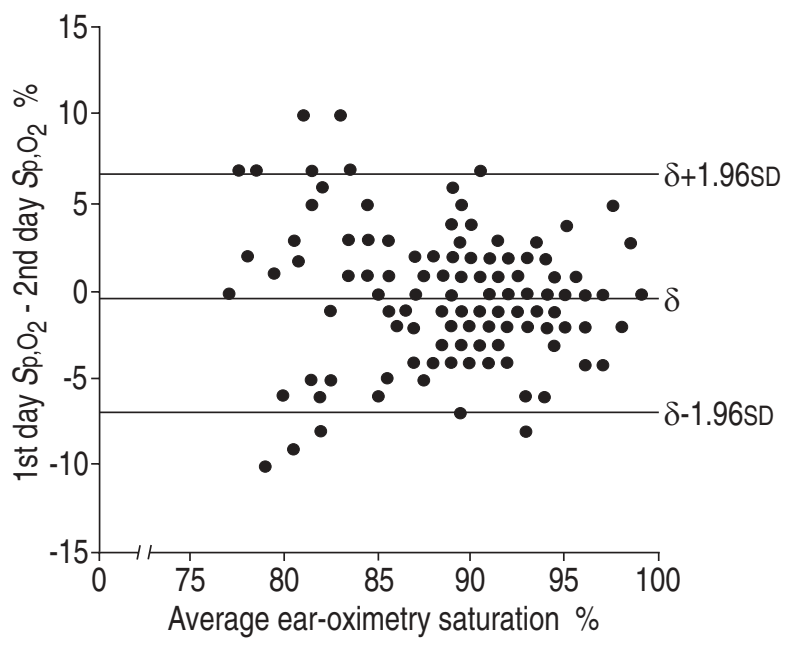

Fig. 2. - Plot of all the values recorded at baseline and at the 2nd, 4 th and 6th minute of each test and measured on two different days with the same protocol by means of ear-oximetry. On the abscissa there is the average saturation value of each pair of measurements ( $\left(1\right.$ st day $\mathrm{Sp}, \mathrm{O}_{2}+2$ nd day $\left.\left.\mathrm{Sp}, \mathrm{O}_{2}\right) / 2\right)$. On the ordinate there is the difference between the two values. First day mean $\mathrm{Sp}_{\mathrm{p}} \mathrm{O}_{2}=89.5 \pm 5.1 \%$. Second day mean $\mathrm{Sp}_{\mathrm{p}} \mathrm{O}_{2}=90.1 \pm 5.0 \% . \delta=-0.23 \pm 3.61 \%(\mathrm{p}=\mathrm{NS}) .1$ st day $\mathrm{Sp}, \mathrm{O}_{2}$ : ear oximetry saturation measured on the first day; 2nd day $\mathrm{Sp}, \mathrm{O}_{2}$ : ear oximetry saturation measured on the second day; $\delta$ : mean bias; SD: standard deviation of the individual differences; $\delta+1.96 \mathrm{SD}$ : upper limit of agreement between the two methods; $\delta-1.96 \mathrm{sD}$ : lower limit of agreement between the two methods. 
Table 3. - Prescriptions of oxygen flow rates based on ear-oximetry and CO-oximetry

\begin{tabular}{lcc}
\hline & \multicolumn{2}{c}{ Oxygen prescription } \\
$\mathrm{Pt}$ & $\begin{array}{c}\text { Ear-oximeter based } \\
\text { L.min }\end{array}$ & $\begin{array}{c}\text { CO-oximetry based } \\
\text { L. }\end{array}$ \\
No. & 6 & 4 \\
\hline $1^{\S}$ & 5 & 5 \\
2 & 3 & 4 \\
$3^{*}$ & 1 & 3 \\
$4^{*}$ & 3 & 3 \\
5 & 5 & 4 \\
$6^{\S}$ & 2 & 1 \\
$7^{\S}$ & 1 & 1.5 \\
$8^{*}$ & 3 & 3 \\
9 & 4 & 3 \\
$10^{\S}$ & 5 & 5 \\
11 & 2 & 2 \\
12 & 0 & 1 \\
$13^{*}$ & 2 & 1 \\
$14 \S$ & 4 & 4 \\
15 & 6 & 5 \\
$16^{\S}$ & 4 & 4 \\
17 & 2 & 2 \\
18 & 4 & 4 \\
19 & 5 & 5 \\
20 & 5 & \\
\hline
\end{tabular}

Pt: patients. §: cases in which the ear-oximeter overestimated the oxygen prescription; *: cases in which the ear-oximeter underestimated the oxygen prescription.

Invasive and noninvasive method-based prescriptions are presented in table 3 . The agreement between prescriptions of oxygen flow rates based on $\mathrm{Sa}_{\mathrm{a}} \mathrm{O}_{2}$ and $\mathrm{Sp}, \mathrm{O}_{2}$ methods was satisfactory in only 10 subjects. In the other 10 subjects, the two prescriptions did not coincide: the ear-oximeter overestimated oxygen supply in six subjects $\left(4.2 \pm 1.8\right.$ versus $\left.3.0 \pm 1.7 \mathrm{~L} \cdot \mathrm{min}^{-1} ; \mathrm{p}<0.0005\right)$ and underestimated it $\left(1.2 \pm 1.3\right.$ versus $\left.2.4 \pm 1.4 \mathrm{~L} \cdot \mathrm{min}^{-1} ; \mathrm{p}<0.01\right)$ in four subjects.

The contingency table analysis with coded raw data for $\mathrm{Sa}, \mathrm{O}_{2}$ and $\mathrm{Sp}, \mathrm{O}_{2}$ is presented in table 4 . The cut-off value of $90 \%$ saturation was achieved by both instruments (which implies the possibility of having the same oxygen flow rate prescription) in 16 cases. In 19 cases, the cut-off value was not reached by either the $\mathrm{CO}$ - or the ear-oximeter. In seven cases, the ear-oximeter overvalued the real saturation and, consequently, the flow rate for an oxygen prescription based on these values would have been overestimated. In the remaining five cases, the ear-oximeter underestimated the $\mathrm{Sa}_{\mathrm{a}} \mathrm{O}_{2}$, so that

Table 4. - Contingency table analysis with coded raw data for $\mathrm{Sa}, \mathrm{O}_{2}$ and $\mathrm{Sp}, \mathrm{O}_{2}$

\begin{tabular}{llccc}
\hline & & $S_{\mathrm{a}, \mathrm{O}_{2}}$ & & \\
& & More & No more & Total \\
\hline$S_{\mathrm{p}, \mathrm{O}_{2}}$ & More & 19 & 7 & 26 \\
& No more & 5 & 16 & 21 \\
& Total & 24 & 23 & 47 \\
& & &
\end{tabular}

$\mathrm{Sa}_{\mathrm{a}, \mathrm{O}_{2}}$ : arterial oxygen saturation; $\mathrm{S}_{\mathrm{p}, \mathrm{O}_{2}}$ : ear oximetry (pulse oximetry) saturation; More: more oxygen flow is needed ( $\mathrm{Sa}_{\mathrm{a}} \mathrm{O}_{2}$ $\leq 90 \%$ and $\mathrm{Sp}_{\mathrm{p}, \mathrm{O}_{2}} \leq 90 \%$ ); No more: no more oxygen flow is needed $\left(\mathrm{S}_{\mathrm{a}, \mathrm{O}_{2}} \geq 90 \%\right.$ and $\left.\mathrm{Sp}_{\mathrm{p}, \mathrm{O}_{2} 2} \geq 90 \%\right)$. Chi-squared $\mathrm{p}<0.005$. For further details see the text.
Table 5. - Contingency table analysis with coded raw data for $\mathrm{Sa}_{2} \mathrm{O}_{2}$ and $\mathrm{Sp}, \mathrm{O}_{2}$ determined by using a cut-off $\mathrm{Sa}, \mathrm{O}_{2}$ of $90 \%$ and a cut-off $\mathrm{Sp}, \mathrm{O}_{2}$ of $93 \%$

\begin{tabular}{llrrr}
\hline & & $S_{\mathrm{a}, \mathrm{O}_{2}}$ & & \\
& & More & No more & Total \\
\hline $\mathrm{S}_{\mathrm{p}, \mathrm{O}_{2}}$ & More & 21 & 18 & 39 \\
& No more & 3 & 5 & 8 \\
& Total & 24 & 23 & 47 \\
& & & \\
\hline
\end{tabular}

For definitions see legend to table 4. Chi-squared $\mathrm{p}=\mathrm{NS}$. For further details see the text.

the flow rate for an oxygen prescription based on these values would have been underestimated. The statistical significance of Chi-squared was $\mathrm{p}<0.003$.

To observe whether, theoretically, a higher $\mathrm{Sp}, \mathrm{O}_{2}$-based cut-off value could have avoided the underestimation of $\mathrm{Sa}_{\mathrm{a}} \mathrm{O}_{2}$ (and consequent failure to prescribe a correct oxygen flow rate), the contingency table analysis was recomputed. Since the average $\mathrm{Sp}, \mathrm{O}_{2}$ at the 6th minute was $88 \pm 5 \%$, the new cut-off $\mathrm{Sp}, \mathrm{O}_{2}$ became this mean value plus its SD, i.e. about $93 \%$. Table 5 presents the contingency table analysis with coded raw data when oxygen flow prescription was performed with a cut-off $\mathrm{Sa}_{\mathrm{a}} \mathrm{O}_{2}$ of $90 \%$ and a cut-off $\mathrm{Sp}_{\mathrm{p}, \mathrm{O}_{2}}$ of $93 \%$. Only three cases were underestimated, whilst 18 were overestimated. The cut-off value was achieved by both instruments in five cases, but in 21 cases it was not reached by either the CO- or ear-oximeter. The Chi-squared had no statistical significance $(\mathrm{p}=\mathrm{NS})$.

Recalculating the oxygen prescriptions for the present group of patients in this way, would have resulted in fewer underestimations of the oxygen prescription (from four cases to only one). Moreover, in the remaining case, the underestimation was only $1 \mathrm{~L}\left(2\right.$ versus $\left.3 \mathrm{~L} \cdot \mathrm{min}^{-1}\right)$. On the other hand, the new cut-off $\mathrm{Sp}, \mathrm{O}_{2}$ obviously led to an increase in the overestimations of oxygen flow rate prescription by, on average, about $0.6 \mathrm{~L} \cdot \mathrm{min}^{-1}$.

\section{Discussion}

The first finding of this study is that the noninvasive measurement of oxygen saturation was not reliable during exercise in the patient population examined. This finding is in line with a number of studies that have documented a low degree of accuracy for the noninvasive assessment of saturation [14-16]. However, the present results contrast with the findings of other investigators, who have found a high degree of accuracy for noninvasive oximeters in normal subjects [20] and in athletes [22] during exercise while breathing room air, in pulmonary patients at rest and during exercise [21], as well as in normal subjects breathing hypoxic mixtures both at rest $[18,19]$ and during exercise [20].

Many of these studies [16, 18-22], however, have suffered from a methodological shortcoming in that they used linear correlations to compare measurements of different devices. Linear regression analysis is misleading, since it measures only the strength of a relationship between two variables and not the agreement between them. In fact, to agree perfectly, the results of the two different methods of measurements would have 
to lie on the line of identity and not along any straight line. Moreover, correlation depends on the range of the true quantity in the sample. Thus, a high correlation does not necessarily imply that the two methods agree, and ignores an obvious systematic error.

In the present study, the data were analysed using the method described by BLAND and Altman [27], which has been shown to be more correct in assessing agreement between two methods of clinical measurement. In fact, if linear correlation had been used, a strong agreement would have been found $(\mathrm{r}=0.8 ; \mathrm{p}<0.0001)$, but, as is shown in figure 1, the method of Bland and Altman [27] showed a clear lack of agreement between the earand CO-oximeter. In fact, the mean bias was statistically different from 0 , and the $95 \%$ CIs were wide: -1.12 to -0.22 for the bias; 4.77 to 6.32 for the upper limit; and -7.66 to -6.10 for the lower one. In view of the wide variability of readings, namely between -7.66 and 6.32 , it can be concluded that the discrepancies between the two oximeters are unacceptable.

The second finding from the present study is that this discrepancy did not make it possible to prescribe oxygen flow rates with a fair degree of accuracy. In fact, in only 10 patients $(50 \%)$ were the prescriptions the same as those made invasively with a CO-oximeter; in four the prescriptions were underestimated and in six more oxygen was given than was necessary.

This adds more information to the issue in question because, although numerous studies have compared invasive versus noninvasive measurements of saturation, none have explored its clinical impact on oxygen prescription.

In view of these results, the logical conclusion would be that assessment of arterial blood samples should be used for prescribing oxygen during exercise in these patients. However, this procedure has to be performed through arterial cannulation, is costly and time-comsuming, besides being invasive, with potential side-effects and risks. One is, thus, led to consider the clinical implications of an incorrect prescription. Giving more oxygen than necessary during exercise is essentially a problem of cost, since we do not see any adverse effect with higher inspiratory oxygen fractions $\left(F_{\mathrm{I}}, \mathrm{O}_{2} \mathrm{~s}\right)$ than necessary during a short period, such as exertion. Under-prescription, on the other hand, involves ethical issues, because of the potential negative impact on the patient's clinical status of an underestimation of oxygen flow rate needs. It is more than desirable to avoid all of the exercise desaturation episodes, each of which results in a temporary reduction in the oxygenation of all the organs and, as a result, could have potentially negative consequences, such as cardiac arrhythmias etc. Moreover, COPD patients on LTOT often complain of dyspnoea, and oxygen has been proved to relieve breathlessness and to increase both exercise tolerance and useful daily activities [7-11].

Thus, in trying to find a compromise between noninvasive methods and precise prescriptions, we would suggest that ear-oximeter should be used but that the level above which exercise desaturation is considered "corrected" should be increased to $93 \%$. In the present case, the $93 \%$ limit of $\mathrm{Sp}, \mathrm{O}_{2}$ would have led to an underprescription in only one out of 20 patients. Conversely, overprescription would have increased (as seen, on average, by about $0.6 \mathrm{~L} \cdot \mathrm{min}^{-1}$ ), leading to greater oxygen waste. However, we do not consider this overestimation to be a serious problem of waste in financial terms. In fact, if one estimates on an empirical basis that the amount of time spent on physically demanding activities is a couple of hours per day, the waste of oxygen would be $70-80 \mathrm{~L}^{-d_{a y}}{ }^{-1}$, which is negligible when compared to the total cost of LTOT (less than $3 \%$ of the daily consumption of oxygen of a COPD patient on LTOT).

In conclusion, we have shown that there are discrepancies both in the readings and oxygen flow rate prescriptions between CO- and ear-oximetry. We have suggested, as working solution, that a new cut-off limit of $93 \% \mathrm{Sp}, \mathrm{O}_{2}$ should be used as the value above which it should be possible to consider the exercise-induced desaturation to be corrected and, consequently, to properly prescribe oxygen during daily life activities.

Acknowledgements: The authors would like to thank the staff of the Pulmonary Function Testing Laboratory (E. Aggio, A. Poma and M. Sacchi) for their most valuable technical assistance.

\section{References}

1. Nocturnal Oxygen Therapy Trial Group. Continuous or nocturnal oxygen therapy in chronic hypoxic lung disease: a clinical trial. Ann Intern Med 1980; 91: 391-398.

2. Medical Research Council working party. Long-term domiciliary oxygen therapy in chronic hypoxic cor pulmonale complicating chronic bronchitis and emphysema. Lancet 1981; i: 681-686.

3. Timms RM, Khaja FU, Williams GW, and the Nocturnal Oxygen Therapy Group. Hemodynamic response to oxygen therapy in chronic obstructive pulmonary disease. Ann Intern Med 1985; 102: 29-36.

4. Weitzenblum E, Sautegeau A, Ehrhart M, Mammosser M, Pelletier A. Long-term oxygen therapy can reverse the progression of pulmonary hypertension in patients with chronic obstructive pulmonary disease. Am Rev Respir Dis 1985; 131: 493-498.

5. Conference Report. Problems in prescribing and supplying oxygen for Medicare patients. Am Rev Respir Dis 1988; 134: 340-341.

6. SEP Task Group. Recommendations for long-term oxygen therapy (LTOT). Eur Respir J 1989; 2: 160-164.

7. Leggett RJE, Flenley DC. Portable oxygen and exercise tolerance in patients with chronic hypoxic cor pulmonale. Br Med J 1977; 2: 84-86.

8. Woodcock AA, Gross ER, Geddes DM. Oxygen relieves breathlessness in "pink puffers". Lancet 1981; i: 907-909.

9. American Thoracic Society. Standards for the diagnosis and care of patients with chronic obstructive pulmonary disease (COPD) and asthma. Am Rev Respir Dis 1987; 136: 225-244.

10. ACCP Conference. ACCP-NHLBI national conference on oxygen therapy. Chest 1984; 86: 234-247.

11. Conference Report. Further recommendations for prescribing and supplying long-term oxygen therapy. Am Rev Respir Dis 1988; 138: 745-747.

12. Kochansky M. Ear oximetry as a method of determining home oxygen prescriptions. Respir Care 1984; 29: 1211-1220.

13. Nelson CM, Murphy EM, Bradley JK, Durie RH. Clinial use of pulse oximetry to determine oxygen prescriptions for patients with hypoxemia. Respir Care 1986; 31: 673-680. 
14. Hansen JE, Casaburi R. Validity of ear oximetry in clinical exercise testing. Chest 1987; 91: 333-337.

15. Clark JS, Votteri B, Ariagno RL, et al. State of the art: noninvasive assessment of blood gases. Am Rev Respir Dis 1992; 145: 220-232.

16. Nickerson BG, Sarkisian C, Tremper K. Bias and precision of pulse oximeters and arterial oximeters. Chest 1988; 93: 515-517.

17. Smyth RJ, D'Urzo AD, Slutsky AS, Galko BM, Rebuck AS. Ear oximetry during combined hypoxia and exercise. J Appl Physiol 1986; 60: 716-719.

18. Rebuck AS, Chapman KR, D'Urzo A. The accuracy and response characteristics of a simplified ear oximeter. Chest 1983; 83: 860-864.

19. Gislason T, Sandhagen B, Daskalopoulou E. Ear oximetry during progressive hypoxia. Uppsala J Med Sci 1988; 93: 45-51.

20. Powers SK, Dodd S, Freeman J, Ayers GD, Samson H, McKnight T. Accuracy of pulse oximetry to estimate $\mathrm{HbO}_{2}$ fraction of total $\mathrm{Hb}$ during exercise. J Appl Physiol 1989; 67: 300-304.
21. Ries AL, Farrow JT, Clausen JL. Accuracy of two ear oximeters at rest and during exercise in pulmonary patients. Am Rev Respir Dis 1985; 132: 685-689.

22. Martin D, Powers S, Cicale M, Collop N, Huang D, Criswell D. Validity of pulse oximetry during exericse in elite endurance athletes. J Appl Physiol 1992; 72: 455-458.

23. McGavin CR, Gupta SP, McHardy GJR. Twelve-minute walking test for assessing disability in chronic bronchitis. Br Med J 1976; 1: 822-823.

24. Butland RJ, Pang J, Gross ER, Woodcock AA, Geddes DM. Two-, six-, and 12 minute walking tests in respiratory disease. $\mathrm{Br}$ Med $J$ 1982; 284: 1607-1608.

25. Knox AJ, Morrison JFJ, Muers MF. Reproducibility of walking test results in chronic obstructive pulmonary disease. Thorax 1988; 43: 388-392.

26. Guyatt GH, Pugsley SO, Sullivan MJ, et al. Effect of encouragement on walking test performance. Thorax 1984; 39: 818-822.

27. Bland MJ, Altman DG. Statistical methods for assessing agreement between two methods of clinical measurement. Lancet 1986; i: 307-310. 